\title{
SURGICAL TREATMENT OF MULTIPLE INTRACRANIAL ANEURYSMS
}

\author{
NELSON MARTELLI - BENEDICTO OSCAR COLLI - JOAO ALBERTO ASSIRATI JR. \\ HELIO RUBENS MACHADO - ROBERTO PARENTE JR.
}

\begin{abstract}
SUMMARY - A retrospective study was conducted on 42 patients with multiple aneurysms surgically treated from 1975 to 1986. Thirty one of them had 2 ancurysms 6 had 3,3 had 4 and 2 had 5 (62 in the internal carotid, 27 in the middle cerebral artery, 11 in the anterior cerebral and 3 in the basilar artery). All patients had subarachnoid hemorrhage and were classified as follows upon admission: 11, grade I; 12, grade II; 15, grade III, and 4, grade IV, and most of them improved before surgcry (29, grade I, 7, grade II, and 6, grade III). In most cases, surgery was delayed and the 42 patients needed 57 graniotomies for clipping the aneurysms. Of the 24 patients with bilateral aneurysms, 15 were operated on both sides (11 are asymptomatic, 1 has hemiparesis, and 3 died later). Qf the 9 patients submitted to unilateral craniotomy, 4 died and 5 are alive and well. Of the 18 patients with unilateral aneurysms, 11 are asymptomatic, 2 have hemiparesis, 1 has diplegia and behavioral disorders, and 4 died. Overall mortality was $26.1 \%$. intraoperative mortality was $11.9 \%$, and no mortaiity occurred among the patients operated over the last 5 years. The management of the these patients is discussed.
\end{abstract}

\section{Tratamento cirúrgico de aneurismas intracranianos múltiplos.}

RESUMO - Foram analisados retrospectivamente 42 pacientes com aneurismas múltiplos $(17,8 \%$ do total de pacientes com aneurismas) atendidos no periodo de 1975 a março de 1986. Vinte e sete eram do sexo feminino e 15 do masculino, com idade variando da terceira à sétima décadas. Trinta e um pacientes tinham 2 aneurismas (15 uni e 16 bilaterais), 6 tinham 3 (2 uni e 4 bilaterais), 3 tinham 4 (todos bilaterais) e 2 tinham 5 (bilaterais), totalizando 102 aneurismas (61 na carótida interna, 27 na cercbral média, 9 no complexo cerebral anterior/comunicante anterior, 3 na basilar e 2 na cerebral anterior distal). Todos os casos foram internados por hemorragia subaracnóidea e 11 foram classificados em grau I, $12 \mathrm{em}$ grau II, $15 \mathrm{em}$ grau III e $4 \mathrm{em}$ grau IV na internação. Os pacientes foram mantidos em repouso absoluto, sob sedação e a evolução prê-operatória mostrou melhora clínica da maioria dos pacientes (29 operados em grau I, 7 em grau II e 6 em grau III). A cirurgia foi realizada tardiamente na maioria dos casos (28 entre o $110^{\circ}$ e 0 30 dia) e os 42 pacientes foram submetidos a 57 craniotomias para clipagem dos aneurismas. Dos 24 pacientes com aneurismas bilaterais, 15 foram operados dos dois lados (11 estão assintomáticos e 1 com hemiparesia e 3 faleceram tardiamente por outras causas que não hemorragia subaracnóidea). Dos 9 pacientes submetidos a craniotomia unilateral, 4 faleceram e 5 estão bem. Dos 18 pacientes com aneurismas unilaterais, 11 estão assintomáticos, 2 apresentam hemiparesia, 1 apresenta diplegia e distúrbios do comportamento e 4 faleceram. A mortalidade global foi de $26,1 \%$ durante todo o seguimento, a mortaliaade operatória foi $11,9 \%$ e não houve mortalidade nos casos operados nos últimos 5 anos. A conduta preconizada para o tratamento destes pacientes é discutida.

Division of Neurosurgery, Department of Surgery, Orthopedics and Traumatology; Hospital das Clínicas, Ribeirão Preto Medical School, University of Săo Paulo. 
Multiple aneurysms are an important part of intracranial vascular pathology since they differ in behavior from single aneurysms by presenting a longer risk of bleeding. Statistical data obtained from angiography and/or autopsy procedures show that the frequency of multiple aneurysms varies from 21 to $33.5 \%$ 5-7,9-11,17,20,22,23,25,28,29,35.36. Pouyanne et al.29 have divided the history of multiple aneurysms into three periods. The first, called anatomical, was that of necroscopic detection and extended until 1944. The second included pioneering efforts in the surgical treatment of aneurysms, whereby the carotid artery was tied in the neck and the ruptured aneurysm was approached directly intracranially when it could be identified. The direct approach to the ruptured aneurysm progressively rained favor, replacing the procedure of carotid ligation in the neck 5,6,10,11,18,23,27,29. The observation of additional bleeding episodes due to rupture of other aneurysms in patients treated for a ruptured aneurysm 11,28 led to the indication of treatment of additional unruptured aneurysms during the same surgical act and through the same craniotomy, as long as this did not expose the patient to additional risks 6,11,23,28. After the results of the Cooperative Study of Intracranial Aneurysms and Subarachnoid Hemorrhage were published in 1966, the natural evolution of intracranial aneurysms was better understood and, owing to the possibility of better evaluation of the surgical possibilities for this very serious condition, a direct bilateral approach to the aneurysms, even unruptured $19,20,29$, started to be widely used and this marked the beginning of the third period in the history of multiple aneurysms. Even though today the direct approach to intracranial aneurysms is considered to be the treatment of choice by most specialists, problems are still extant with respect to the conduct to be adopted for patients with this condition because of the diversity of factors involved, as age, general condition, associated pathologies, was there subarachnoid hemorrhage?, what aneurysm ruptured?, when to operate?

The objective of the present paper is to report our experience with the treatment of a group of patients with multiple aneurysms and to describe our conduct with respect to this pathology based on the evolution of these cases.

\section{MATERIAL AND METHODS}

We analyzed retrospectively the medical records of 42 patients admitted to the University Hospital of the Faculty of Medicine of Ribeirão Preto with a diagnosis of multiple aneurysms and submitted to surgical treatment from January 1975 to March 1986 . These 42 patients corresponded to $17.8 \%$ of all patients operated for intracranial aneurysms at the University Hospital during this period. Arterial hypertension was a frequently associated pathology in these cases. Table 1 shows patient distribution by age and frequency of arterial hypertension by sex. The patients were considered to have arterial hypertension when there were signs of this condition before the subarachnoid hemorrhage (SAH) episode. Twenty eight patients were white, and 14 were black. Thirty one patients had 2 aneurysms (15 unilateral and 16 bilateral), 6 had 3 (2 unilateral and 4 bilateral), 3 had 4 (bilateral), and 2 had 5 (bilateral). The patients were distributed as follows according to the number and anatomical distribution of the aneurysms (2s):

Group 1 - Unilateral Double Aneurysms (17): A, internal carotid-middle cerebral arteries (5); B, internal carotid-anterior communicant arteries (1); C, middle cerebral-anterior commu-

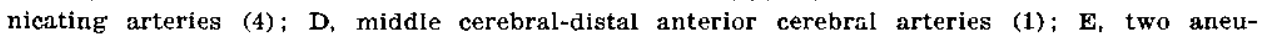
rysms on the same trunk (5); F, internal carotid-basilar arteries (1).

Age (years)

\begin{tabular}{|c|c|c|c|c|c|c|c|c|c|c|c|c|}
\hline \multirow{2}{*}{ Sex } & \multicolumn{2}{|c|}{$20-30$} & \multicolumn{2}{|c|}{$30-40$} & \multicolumn{2}{|c|}{$40-50$} & \multicolumn{2}{|c|}{$50-60$} & \multicolumn{2}{|c|}{$60-70$} & \multicolumn{2}{|c|}{ Total } \\
\hline & $\mathrm{N}$ & $\mathrm{AH}$ & $\mathrm{N}$ & AH & $\mathrm{N}$ & $\mathbf{A H}$ & $\mathrm{N}$ & AH & $\mathbf{N}$ & AH & $\mathbf{N}$ & AH \\
\hline Male & 5 & 0 & 0 & 3 & 2 & 2 & 2 & 0 & 0 & 1 & 9 & 6 \\
\hline Female & 4 & 2 & 2 & 3 & 5 & 4 & 1 & 5 & 0 & 1 & 12 & 15 \\
\hline \multirow[t]{2}{*}{ Total } & 9 & 2 & 2 & 6 & 7 & 6 & 3 & 5 & o & 2 & 21 & 21 \\
\hline & \multicolumn{2}{|c|}{11} & \multicolumn{2}{|c|}{8} & \multicolumn{2}{|c|}{13} & \multicolumn{2}{|c|}{8} & \multicolumn{2}{|c|}{2} & \multicolumn{2}{|c|}{42} \\
\hline
\end{tabular}

Table 1 - Age distribution of patients with multiple aneurysms and frequency of arterial hyportension in relation to sex. $N$, normotensive; $A H$, arterial hypertensive. 
Group 2 - Symmetrical Bilateral Double Aneurysms (10): A, internal carotid arterics (9); B, middle cerebral arteries (1).

Group 3 - Asymmetrical Bilateral Double Aneurysms (4): A, internal carotid-middle ccrebral arteries (4).

Group 4 - Three or More Aneurysms (11): A, unilateral (3); B, bilateral (8).

The 42 patients showed 102 aneurysms distributed as follows: 61 on the internal intracranial carotid artery, 27 on the middle cerebral artery, 9 on the communicant-anterior cerebral complex, 3 on the basilar artery, and 2 on the distai anterior cerebral artery. The diagnosis of multiple aneurysms was made by angiography in 39 cases, owing to further bleeding in 2 cases, and at autopsy in 1 case. The patients were classified clinically by the system of Hunt and Hess (13).

\section{RESULTS}

Clinical manifestations - All patients suffered one or more SAH episodes before hospitalization. Fourteen patients were hospitalized during the first 2 days after the hemorrhage, 23 by the 5th day, 27 by the 7 th day, 37 by the 20th, and 3 after the 20th day. The clinical manifestations observed during or after SAH were sudden headache in 40 patients, neck stiffness in 39 , loss of consciousness in 10 , mental confusion in 8 , drowsiness, hemiparesis and lesion of the III cranial nerve in 6 , convulsive seizure in 3 , blurred vision in 2 , papiliary edema in 1 , and decreased visual acuity in 1 . In 5 cases the SAH episode was related to physical effort (2 while washing clothes, 1 during coltus, 1 during evacuation, and 1 while jumping off a truck). Upon admission, 11 patients were classified clinically as grade I, 12 as grade II, 15 as grade III, and 4 as grade IV.

Preoperative evolution - All patients were maintained under conditions of absolute rest in bed, medicated with antihypertensive drugs and laxatives when necessary and sedated with barbiturates, phenothiazine or benzodiazepine drugs. Periodic punctures were performed to extract cerebrospinal fluid (CSF) and when hypertension was present a sufficient volume was removed to reduce the initial CSF pressure by half. After the systematic adoption of these measures, one suffered further bleeding on the 5th day post-hemorrhage, and another who had refused surgical treatment suffercd a new hemorrhagic episode 22 days after the first (while at home). During the preoperative period, vasoespasm was suspected in 4 patients; in 1 there was angiographic confirmation, and in the other 3 the CSF puncture negative for bleeding and the clinical evolution suggested this occurrence. Three patients evolved well with the use of plasma expanders, and the other shoved serious sequelae (behavioral disturbances and brachial and crural diplegia). Patient evolution after admission was stable or favorable and immediately before surgery 29 patients were grade I, 7 were grade II, and 6 grade III.

Angiography - In most cases, preoperative angiography was performed late in relation to the SAH (3 between the 1st and 5 th day, 7 between the 6 th and 10 th day, 11 between the 11 th and 15th day, 7 between the 16th and 20 th day, 6 between the 20 th and 25 th day, and 8 after the 25th day). Thirty two patients were submitted to bilateral carotid angiography, 1 to unilateral carotid angiography, and 9 to bilateral and vertebral carotid angiography. In 10 patients, vertebral angiography was performed during the postoperative period together with the control carotid angiography. In the 23 patients submitted to bilateral carotid angiography, 91 aneurysms were detected, and in the 19 patients submitted to vertebral angiography, 1 aneurysm of the basilar artery was detected. In a female patient submitted to unilateral carotid angiography, one aneurysm was detected and the patient died 6 months later due to a new SAH. The bilateral carotid angiography performed at this time showed an aneurysms of the contralateral internal carctid which had bled, and the previous aneurysm was excluded from the circulation with a clip. During surgery, one additional aneurysm of the intracranial carotid artery was detected in 3 patients. These aneurysms had not been detected by angiography. In 2 other patients, one aneurysm of the middle cerebral artery and one of the carotid bifurcation, which had not been visualized when the angiography was first analyzed, were respectively identified at autopsy and during the review of the anglography during the preparation of the present study. In 1 patient with 3 angiographycally suspected aneurysms, one which was thought to be located on the intracranial carotid artery was not detected during surgery. In 2 cases, bilateral carotid angiography revealed only 1 aneurysm. One of these patients had an aneurysm of the left 
middle cerebral artery and a small $2 \mathrm{~mm}$ aneurysm on the internal carotid artery close 10 posterior communcatins artery which increased in s.ze and ruptured 11 months later. The other patient had an aneurysm of the anterior communicant artery and died 24 days after clipping: autopsy revealed the presence of 1 aneurysm of the middle cerebral artery (which had not been visualized angiographically) and 2 of the basilar artery (which was not explored angiographically). Bilateral vasospasm was observed in 4 cases and a unilateral one in 8 . Of these 12 patients, only 1 was submitted to angiography during the first week (on the day of bleeding because of a suspected intracerebral hematoma), whereas the other 11 were submitted to angiography between the 8 th and $15^{\text {th }}$ day (7) and after the 15 th day (4). In 7 cases, after vasospasm, control angiography was repeated with a minimum 6-day interval and a maximum 22-day interval after the first, and in 3 cases the vasospasm still was present. Two hematomas of the rylvian fossa amoug 3 detected at surgery had been suspected angiographically and resulted from the rupture of 1 aneurysm of the middle cerebral artery and of 1 aneurysm of the internal carotid artery (as confirmed at surgery). Nine patients showed sions of bilateral and symmetrical hydrocephalus during the first angiography, and 3 of them required a ventriculoperitoneal shunting.

Identification of the ruptured aneurysm - For 32 of the 40 patients whosc angiographies showed more than 1 aneurysn it was possible to suspect which aneurysm had bled. In 16 of these cases the suspicion was confirmed during surgery, in 12 no signs of bleeding were observed during surgery, in 1 the aneurysm that bled was not the suspected one, and in another the side of the suspected aneurysm was not surgically explored (the patient died after the first surgery). In 2 cases identification was impossible because of the proximity of the aneurysms. In 8 patients for whom angiography did not permit a prediction of which aneurysm had ruptured, the identification was made by signs of bleeding during surgery in 2, and identification was not possible in the remaining 6 due to the absense of signs of bleeding or to the proximity of the aneurysms. Of the 5 paticnts who showed hemiparesis of brachio-facial predominance, rupture of an aneurysm of the middle cerebral artery was confirmed during surgery in 1 , the identification was not possible due to the absense of signs of bleeding or to the proximity of the aneurysms in 3 , and the suspected side was not surgically explored in 1 (there was an aneurysm of the internal carotid artery on the suspected side but the patient died after the first surgery performed to clip 2 aneurysms on the opposite side). In 1 patient, the suspected rupture of an aneurysm of the posterior communicant artery owing to the presence of a lesion of the III cranial nerve was confirmed surgically. In 1 patient who suffered a lateralized seizure the suspected affected side could not be confirmed because there were bilateral aneurysms and no signs of blecding were found during the surgical acts. In 4 cases it was not possbile to suspect which aneurysm had bled on the basis of clinical history, angiography or surgery.

Surgeries - The 42 patients were submitted to 57 craniotomies (uni or bilateral) for a direct approach to, and clipping of the aneurysrss. Surgical access was by fronto-temporal (pterional)(34) craniotomy in all cases but 1 , who was submitted to frontal medial craniotomy to approach an aneurysm of the anterior communicant artery, and another who was submitted to wide fronto-temporal craniotomy going beyond the midline to approach an aneurysm of the anterior communicant artery and an aneurysm of the distal anterior cerebral artery. During dissection of the aneurysm, arterial hypotension controlled with sodium nitroprusside was used routinely (mean arterial pressure around $60 \mathrm{~mm} / \mathrm{Hg}$ ). A lumbar puncture was performed in all cases at the beginning of the surgical procedure and a coupled catheter was left in place for CSF removal if necessary to facilitate retraction of the brain. Surgery was performed before the 10 th day after hemorrhage in 2 patients, from 11 to 20 days in 14, from 21 to 30 days in 14, from 31 to 40 days in 8 and after the 11st day in 4 . Of the 24 patients with bilateral aneurysms, 15 were submitted to bilateral craniotomy to approach all of them, and the remaining 9 were submitted to unilateral craniotomy. Three died after the first surgery, 2 refused the second surgery, 2 are currently waiting for the second surgery, 1 was submitted to unilateral angiography due to lesion of the III cranial nerve and an aneurysm on the opposite side was not identified, and 1 was submitted to common carotid ligation in the neck due to a contralateral aneurysm: In 4 of the 31 craniotomies performed for direct approach to and clipping of the aneurysms, this objective was not achieved. In 2 patients with lar@e ancurysms of the internal carotid, the neck was partially subdural and the aneurysms ruptured during dissection; hemostasis was obtained by placing a clip which compressed both the neck of the aneurysm and the carotid. In another patient who had two aneurysms very close to each other (bifurcation of the carotid artery and beginning of the middle cerebral artery), owing to rupture of the aneurysm of the bifurcation of the carotid artery during dissection, a clip was applied 
compressing the neck of the aneurysm of the bifurcation and the initial portion of the middle cerebral artery, thus excluding both aneurysms from the circulation. Anastomosis of the superficial temporal with the middle cerebral artery was then performed successfully. The fourth patient had a sessile aneurysm of the left middle cerebral artery which was submitted to trapping. In the 15 patients submitted to bilateral craniotomies, the second surgery was performed during the same hospitalization in 11 cases at intervals of 0 to 25 days between the first and the second intervention. The 4 other patients were discharged and returned for the second operation 36 days and 2,7 and 13 months after the first, respectively. In the 18 patients with unilateral aneurysms all the lesions were clipped, except for 1 aneurysm of the carotid bifurcation which was identified only during revision of the angiographies in the course of the present study. In 21 of the 57 craniotomies performed in the 42 patients, SAH signs were observed and in 15 of these it was possible to identify the aneurysm that had bled. On 6 occasions it was not possible to identify which of the aneurysms ruptured despite signs of hemorrhage becausc of the proximity of the aneurysms. Two patients were submitted to ventriculoneritoneal shunting due to hydrocephalus before approaching the aneurysms, and 1 after appproaching them. A female patient was subnitted to external ventricular shunting to relieve intracranial hypertension after a hemorrhage caused by an aneurysm of the right internal carotid artery which occurred 5 months after clipping an aneurysm of the left internal carotid artery.

Postoperative complications - Twenty two patients were submitted to postoperative angiography to determine the position of the clips or to diagnose complications. These angiographies were performed from the 1st to the 34 th postoperative day, and predominantly from the 7 th to the 12th day (12 cases). Control angiography showed partial clipping of the aneurysmal neck in 2 cases, expansive lesions of the temporal lobe (edema or contusion) in 4 cases, only one of whom required surgical intervention, a postoperative extradural hematoma in 1 patient, and vasospam in 2 ( 8 and 9 days after surgery). Four patients were submitted to postoperative computerized tomography; one for control and three for a suspected expansive process. Edema and contusion of the temporal lobe were found in 2 patients, a frontal intracerebral hematoma occurring after surgery for an aneurysm of the anterior communicant artery was found in 1 and requircd surgical draining, and a small hematoma in the Sylvian fissure with no clinical manifestations was found in 1. Four patients were reoperated immediately after the first surgery for clinically suspected expansive damage ( 3 in the temporal lobe and 1 in the frontal lobe), with an intratenporal hematoma being detected in one of them and cerebral contusion and edema in the others. One patient was reoperated 7 months after the first surgery for repositioning of the clip which partially nccluded the neck of an aneuryem of the internal carotid artery. A total of 8 patients had to be reoperated due to surgical complications. One was rcoperated 3 times due to extradural hematoma, extradural abscess and cranioplasty, 1 was reoperated twice because of cerebral edema and cranioplasty, 3 were reoperated once due to cerebral edema, 1 was reoperated once due to intracerebral hematoma, and 1 was reoperated once for repositioning of the clip.

Postoperative clinical evolution - Of the 15 patients out of the 24 with bilateral aneurysms who were operated bilaterally, 14 are currently asymptomatic after a follow-up of 6 months to 6 years and 9 months (mean: 30 months), and 1 has heminaresis 8 months after surgery. Of the remaining 9 patients, 4 died after the first surgery, 3 refused a second surgery (2 of them are asymptomatic after 5 years and 2 years and 9 inonths, respectively, and one has a full hemiparesis as a sequela occurring 8 years and 9 months ago), 1 is waiting for a second surgery and has been asymptomatic for 2 years and 8 months, and 1 who was submitted to one side craniotomy and to ligation of the contrulateral carotid artery has been asymptomatic for 2 years. Twelve of the 18 patients with unilateral aneurysms are asymptomatic after a follow-up of 7 months to 8 ycars and 6 months (mean: 82.9 months), 1 has a hemiparesis 6 years after clipping of an ancurysm of the middle cerebral artery, 1 has diplegia and behavioral disorders resulting from a preoperative vasospasm and 4 died after surgery.

Mortality - Overall mortality was $19 \%$ (8 patients), with identical percentages for individuals with bilateral and unilateral aneurysms. Intraonerative mortality was $11.9 \%$. Female mortality was $25.9 \%$ (7 patients) and male mortality was $6.67 \%$ (1 patient). Three of the patients with double aneurysms died $(2 \pi .3 \%)$. Mortality was $21.6 \%$ among the patients submitted to unilateral craniotomy, and zero among those submitted to bilateral craniotomy. Among the 8 patients who died, the cause was postoperative complications for 3 , a nex episode of SAH for 3, a probable SAH for 1 , and 1 died during the induction of anesthesia 
for a control angiography. Autopsy of this patient showed, in addition to a clipped aneurysm of the anterior communicant artery, an aneurym of the left miadle cerebral artery and 2 sessile aneurysms of the trunk of the basilar artery. Three patients died later of causes not related to SAH or to surgery, 4 years and 3 wonths, 4 years and 8 months and 4 years and 11 months after the first surgery, respectively. Intraoperative mortality has been zero for the last 5 years.

\section{COMMENTS}

The percentage of multiple aneurysms observed in the present cases $(17.8 \%)$ agrees with values reported for large series $5-7,9,10,17-24,28,29,32,35,36$. The predominance oi temale patients $(64.3 \%)$ has been reported by most authors $18,22,25$, though some llave reported male predominance $11,29,35$. The hignest incidence of multiple aneurysms occurred during the 5th and 6th decades $(50 \%)$, in agreement with observations reported in the literature $18,21,22,29,30,32,35$ and similar to the distribution of single aneurysms $9,16,35,36$. Pouyanne et al.29 have reported several pathologies that may be associated with multiple aneurysms, such as arterial hypertension, polycystic kidneys, aortic coarctation, anatomical variations in the circle of Willis, arteriovenous aneurysms, Usler disease. Among them, the most important is arterial hypertension, whose frequency of association with multiple aneurysms varies from 7 to $44 \% 13,18,21,23,28$, and is higher than in patients with single aneurysms 24,25 . In the present study we observed arterial hypertension in $50 \%$ of all cases, with predominance among women. $\mathrm{Pa}-$ tients with muituple aneurysms show 2 aneurysms in 30 to $95 \%$ of the cases and 3 or more in $5.0 \% 1,0,11,12,16,10,21,23,28$, and their localization varies from 19.2 to $46 \%$ in the middle cerebral artery, 31 to $69 \%$ in the internal carotid artery, 9.8 to $34 \%$ in the anterior cereoral-anterior communicant artery complex and up to $3 \%$ in the posterior circulation $2 x, 21,28$. This wide variation is explained by the different research approaches (autopsy, angiography or surgery), by the number of vessels studied in the anglogram and by the ditrerences among populations. Among our patients, $73.8 \%$ had aouble aneurysms, and $26.1 \%$ had 3 or more, distributed as follows: $59.8 \%$ in the internal carotid artery, $26.5 \%$ in the middle cerebral artery, $8.8 \%$ in the anterior cerebral-anterior communicant artery complex, $2.9 \%$ in the posterior circulation, and $2 \%$ in the distal anterior cerebral artery, in agreement with the averages reported in the literature.

During the preoperative period the patients were submitted to standard clinical treatment (beu rest, sedation and antihipertensive medication when necessary). Other measures taken were repeated CSF punctures to relieve intracranial hipertension in patients without signs of expansive damage and also to accelerate removal of blood from the CSF, which is known to be a spasmogenic factor. These measures were taken at varying intervals according to pressure levels and to the appearance of the $\mathrm{CSF}$ during the preceding puncture and to clinical symptomatology (intensity of neck stiffness and of headache). In most patients the punctures were followed by immediate relief of the headache and improved the consciousnes level. No complications occurred with the use of repeated punctures that reduced by half the initial liquor pressure, even though theoretically a decrease in intracanial pressure may favor further bleeding. With the systematic use of these measures, only l episode of further bleeding occurred in 1 hospitalized patient and in an outpatient who had refused surgery.

Bjorkensten and Halonen 7 reported $22 \%$ multiple aneurysms in patients with $\mathrm{SAH}$ whose 4 cerebral vessels were explored angiographically. Perret and Nishiuka 26 observed an average of $19 \%$ multiple aneurysms when analysing the angiographies included in the Cooperative Study of Aneurysms and Subarachnoid Hemorrhage and found no obvious correlation between the frequency of aneurysms and the number of vessels visualized angiographically. We believe that the angiographic visualization of the 4 vessels is important in the diagnosis of multiple aneurysms on the basis of the relatively high frequency of these cases and of our observations with SAH whose angiography was incomplete and who later suffered a new $\mathrm{SAH}$ due to rupture of another aneurysm. The first carotid angiography for each patient was most often performed at the end of the second or third week after SAH, with an attempt made to avoid the critical phase of vasospasm (which was observed in $33 \%$ of all cases). Perret and Nishioka 26 reported a slight increase in diagnostic positivity when angiography is performed during the second week in relation to the first, although a greater number of complications occurred in the delayed angiographies when compared to those performed during the first week. 
A ruptured aneurysm can be identified by clinical signs, by the EEG 4,9, by angiography $1,11,1421,32$, and by computerized tomography $1,2,21,32$, as well as intraoperative observation. Paralysis of the oculomotor nerve identifies the presence of a ruptured aneurysm in $100 \%$ of cases, aphasia in $80 \%$, and lateral motor deficiency in $64 \%$ (Martilla and Heiskenen, quoted by Pouyanne et al.29). Homolateral hemiparesis should be attributed to a particular arrangement of the circle of Willis associated with the corresponding arterial spasm 29. Bleeding of an aneurysm of the middle cerebral artery was confirmed surgically in $20 \%$ of the present patients who showed hemiparesis with braquiofacial predominance (the proximity of the aneurysms did not permit identification of the ruptured aneurysm in the others) and ruptures of aneurysms of the posterior communicant artery were confirmed in the 6 patients who showed damage to the oculomotor nerve. Angiographic identification of a ruptured aneurysm was possible in 58 to $96 \%$ of cases $1,11.21$, on the basis of the following criteria: presence of hematoma, size shape and irregularity when contrast was used, physiological changes in the circulation such as spasms, and variation in shape in repeated angiographies $14,22,23$. In the present series, these features permitted a suspected diagnosis of ruptured aneurysm in $76.2 \%$ of cases, $50 \%$ of which were confirmed during surgery. In $3.1 \%$ of cases the bleeding aneurysm was not that suspected on the basis of angiography, in $37.5 \%$ there was no sign of bleeding during surgery, and in $3.1 \%$ the suspected side was not explored. The observation of intracerebral hematomas did not always permit the identification of a ruptured aneurysm, since in one case there were 2 very close aneurysms whose morphological characteristics were similar (hematoma of the Sylvian fossa). Identification of a ruptured aneurysm was also impossible in $75 \%$ of cases in which a tentative angiographic diagnosis could not be made because of the proximity of the aneurysms or because there were no signs of bleeding, probably owing to delayed surgical intervention. An angiographically detected vasospasm did not contribute significantly to the localization of the ruptured aneurysm. Computerized tomography can detect SAH at high frequency during the first days $2,21,23$, and locate the ruptured aneurysm in $45 \%$ of cases 21 , on the basis of the presence of localized blood collections or of contrasting of the aneurysm, 21,23. On the basis of clinical and arteriographic signs, Martilla and Heiskenen, quoted by Pouyanne et al.29, obtained $97 \%$ identification of a ruptured aneurysm, Almaani and Richardson ${ }^{1}$ obtained $77.3 \%$ using angiography, EEG and computerized tomography, and Nehls et al.21 obtained $97.5 \%$ using clinical signs, angiography, EEG, and computerized tomography. In $11.9 \%$ of the present cases the ruptured aneurysm could not be identified on the basis of clinical signs, angiography or surgical observation.

Patient treatment was based on clipping all the aneurysms using a unilateral approach (starting with the ruptured one) when the aneurysms were unilateral or when some of them were located along the midline, and using a bilateral approach at different times when the aneurysms were bilateral, as recommended by several investigators $14,19,20,29,31$. In 3 cases we were unable to clip exclusively the aneurysms, with the need to perform a trapping in 2 of them and clipping the carotid artery close to the aneurysm, whose neck was partially infraclinoid, in the other. The postoperative complications observed resulted for the most part from contusion and/or localized edema of the brain parenchyma, especially the temporal lobe, during retraction for opening the Sylvian fissure and exposing the middle cerebral artery (6 contusions/edemas and 2 intracerebral hematomas, 4 and 1 of which respectively caused clinical problems requiring surgical intervention). The vasospasm observed in 2 cases in the control angiography had no clinical repercussions. The risk of enlargement and rupture of an aneurysm whose neck was partially clipped has been reported by Drake and Vanderlinden 8 . In the 2 cases in which the neck of an aneurysm was partially clipped, one was reoperated for clip repositioning and the other patient died before reoperation.

The long-term evolution (more than 1 year) of patients with multiple aneurysms submitted to treatment by direct intracranial approach is considered good (without neurological deficits) or satisfactory (with minimal neurological deficits that do not interfere with work) in $33.8 \%$ to $94 \%$ of cases $11,19,20,28$, varying according to the number of aneurysms treated and the clinical condition of the patient 19,20,28. Among the present patients whose aneurysms were all clipped (only 2 with a follow-up of less than one year), postoperative evolution was good in $78.8 \%$, satisfactory in $6.1 \%$, poor in $3.0 \%$, and $12.1 \%$ died. Nine patients underwent partial unilateral surgeries. Four 
of them are doing well $(44.4 \%), 1$ is doing satisfactorily $(11.1 \%)$, and the remaining 4 died after the first surgery $(44.4 \%)$. Our overall results were good in $71.4 \%$ of cases, satisfactory in $7.1 \%$, poor in $2.4 \%$, and $19.0 \%$ died.

The natural evolution of patients with multiple aneurysms involves 56 to $64 \%$ mortality 15,18,25, in contrast to intraoperative mortality, which varies with clinical condition of the patient and number of aneurysms operated -8 to $50 \% 9,12,18$ - even though some investigators have reported zero mortality 19,20. The conduct of direct intracranial approach to multiple aneurysms, including unruptured symptomatic and incidental ones $14,19,20,25,29,31$, has been progressively adopted, although other authors 12 have doubted that a better prognosis is obtained when the patient is submitted to a second intervention to reach unruptured aneurysms. All but one of our patients were deliberately operated after 10 days from the SAH enisode, a time when operative mortality and morbidity are lower 13 . Most of the patients $(85.7 \%)$ were operated while in clinical grade I or II ("good risk") but there was no relationship between mortality and operative evolution and clinical preoperative condition. Overall mortality in the present series was $19 \%$ and surgical mortality was $11.9 \%$, values that are compatible with those reported in the literature. Overall and surgical mortality were predominant among women (25.9 and $14.8 \%$, respectively, vs. 6.7 and $6.7 \%$ for men), in contrast to the surgical mortality reported by Paterson and Bond 21 , which was $47 \%$ for women and $52.5 \%$ for men. Overall mortality was higher also among patients with more than 2 aneurysms $(30.4 \%)$ than among patients with 2 aneurysms $(12.9 \%)$. Three patients died of commonly occurring postoperative complications (pulmonary infection and cardiopathy) and 1 died during the induction of anesthesia. In one of these patients, who was operated upon for a sessile aneurysm of the left internal carotid artery, the clip applied to the aneurysm, which was properly placed during surgery, was found to be loose at autopsy, showing that for these types of aneurysms methods other than direct clipping are often neccssary.

The occurrence of further bleeding due to rupture of another aneurysm in patients with multiple aneurysms who suffered a previous ruptured aneurysm treated by a direct approach has been reported by several investigators 12,20,28. Heiskenen and Martilla 12 observed further SAH in $10 \%$ of these cases, with $37.5 \%$ mortality over a period of 4 months to 11 years. Drake and Vanderlinden 8 , in a study of the delayed consequences of incomplete surgical treatment of aneurysms (partial clipping of the neck of the aneurysm), noted that the partially clipped aneurysm may become enlarged and rupture. In one of the cases in which a further bleeding episode occurred, this was due to the rupture of another undiagnosed contralateral aneurysm, and the other was due to the rupture of lobulations observed in the middle cerebral artery and close to the clipped aneurysm, or to the rupture of a contralateral aneurysm, since the previous angiography had shown a bilateral vasospasm and aneurysms on one side only. The former case represents important evidence for the need of full brain angiography in patients showing one aneurysm, and in the latter the angiography may have been erroneously interpreted in the presence of a vasospasm. In another patient submitted to clipping of the neck of a paraclinoid aneurysm and whose clip also occluded the carotid artery, the new hemorrhage may have been caused by the rupture of a contralateral non-operated aneurysm or by partial clipping of the paraclinoid aneurysm. In the remaining patient, the new bleeding episode occurred because of the rupture of a small (less than $2 \mathrm{~mm}$ ) aneurysm of the emergence of the posterior communicant artery which increased in size and ruptured 11 months after surgery for a contralateral aneurysm and which motivated angiographic follow-up every 6 months to 1 year of these patients and of those with infundibular dilatation of the posterior communicant artery, as recommended by Moyes 20 .

Conclusions - After analyzing the behavior and evolution of a group of patients with multiple aneurysms who had an episode of subarachnoid hemorrhage and were treated by intracranial approach to, and clipping of the aneurysms, we summarize the conduct adopted in these cases. 1) After SAH diagnosis by examination of the CSF, the patient is maintained under absolute rest, sedated and medicated to control arterial pressure when necessary. 2) Angiography is performed during the second or third week after the hemorrhage, except in cases of suspected hematoma or vasospasm. Over the last 2 years, patients in this situation have been submitted to computerized tomography. Bilateral carotid angiography and at least one vertehral angiography are performed routinely before or after surgery. 3) Once the multiple aneurysms have been identified, we indicate treatment of all aneurysms by a direct 
approach anci by neck clipping whenever possible, generally starting with the ruptured aneurysm, wrich is evidenced by clinical and angiographic manitestations. 4) Unilateral and midline aneurysms are approached by a single craniotomy during the same surgical intervention and the bilateral aneurysms are operated upon in two phases. Whenever possible, the second approach was made soon after appropriate healing of the first. 5) Sugery is performed at the end of the second or during the third week after the bleeding episode, with patients in grades I and II or stabilized in grade III. The usual approach is pterional craniotomy and microsurgical techniques are employed. 6) The patients showing small aneurysms or infundibular dilatation of the posterior communicant artery homolateral to another aneurysm are systematically explored during the surgical intervention. When these changes are contralateral, the patients are followed by periodic angiography at 6-month to I-year intervals for evaluation of their evolution.

\section{REFERENCES}

1. Almaani WS, Richardson AE - Nultiple aneurysms: identifying the ruptured lesion. Surg Neurol 9:303, 1978.

2. Adams HP Jr, Kassel NF, Torner JC - CT and clinical correlations in recent aneurysmal subarachnoid hemorrhage: a preliminary report of the Cooperative Aneurysm Study. Neurology 33:981, 1983.

3. Andrews RJ, Spiegel PK - Intracranial aneurysms: a sex, blood pressure, and multiplicity in an unselected series of patients. J Neurosurg 51:27, 1979.

4. Beatty RA, Richardson AE - The value of eletroencephalography in management of multiple intracranial aneurysms. J Neurosurg 30:150, 1969.

5. Bigelow $\mathrm{NH}-$ Multiple intracranial arterial aneurysms: an analysis of their significance. Arch Neurol Psychiat 73:76, 1955.

6. Bjorkensten GA, Troupp H - Multiple intracranial aneurysms. Acta Chir Scand $118: 387,1959 / 1960$.

7. Bjorkensten GA, Halonen V - Incidence of intracranial vascular lesions in patients with subarachnoid hemorrhage investigated by four vessel angiography. $J$ Neurosurg $23: 29, \quad 1965$.

8. Drake CG, Vanderlinden RG - The late consequence of incomplete surgical treatment of cerebral aneurysms. J Neurosurg 27:226, 1967.

9. Graf CJ - Prognosis for patients with non-surgically treated aneurysms: analysis of the Cooperative Study of Intracranial Aneurysms and Subarachnoid hemorrhage. J Neurosurg 35:438, 1971.

10. Hamby WB - Multiple intracranial aneurysms: report of treatment. $\mathbf{J}$ Neurosurg $16: 558,1959$.

11. Heiskenen O Multiple intracranial aneurysms. Acta Neurol Scand 41:356, 1965.

12. Heiskenen $O$, Martilla 1 - Risk of rupture of a second aneurysm in patients with muitiple aneurysms. J Neurosurg 32:295, 1970.

13. Hunt WE, Hess RM - Surgical risk as related to time of intervention in the repair of intracranial aneurysms, $J$ Neurosurg 28:14, 1968.

14. Jackson FE, Pratt RB, Back JB, Fleming PM, Juteau L - Multiple intracranial arterial aneurysms: current thougths about diagnosis and treatment. Military Med $139: 37,1947$.

15. Jane JA, Kassel NF, Torner JC, Winn HR - The natural history of aneurysms and arteriovenous malformations. J Neurosurg 62:321, 1985.

16. Locksley HB - Report on the Cooperative Study of Intracranial Aneurysms and Subarachnoid Hemorrhage. Section V, Part I. Natural history of subarachnoid hemorrhage, intracranial aneurysms and arteriovenous malformations. Based on 6368 cases in the Cooperative Study. J Neurosurg 25:219, 1966. 
17. McKissock W, Paine KWE, Walsh L - An analysis of the results of treatment of ruptured intracranial aneurysms: report of 772 consecutive csses. J Neurosurg 17:762, 1960 .

18. McKissock W, Richardson A, Walsh L, Owen E - Multiple intracranial aneurysms. Lancet $1: 623,1964$.

19. Mount LA, Brisman $\mathrm{R}$ - Treatment of multiple intracranial aneurysms, J Neurosurg $35: 728,1971$.

20. Moyes PD - Surgical treatment of multiple aneurysms and of incidentally discovered unruptured aneurysms. J Neurosurg $35: 291,1971$.

21. Nehls DG, Flom RA, Carter LP, Spetzler RF - Multiple intracranial aneurysms: determining the site of rupture. J Neurosurg 63:342, 1985 .

22. Ostergaard JR, Hog E - Incidence of multiple intracranial aneurysms: influence of arterial hypertension and gender. $J$ Neurosurg $63: 49,1985$.

23. Overggard J, Rushed $J$ - Multiple cerebra! saccular aneurysms. Acta Neurol Scand $41: 363,1965$.

24. Paillas JE, Bonnal J, Pellegrin J, Sedan R - Les anevrysmes intracraniens multiples. Neuro-Chirurgie 2:271, 1956.

25. Paterson A, Bond MR - Treatment of multiple intracranial arterial aneurysms. Lancet $1: 1302,1973$.

26. Perret G, Nishioka H - Report on the Cooperative Study of Intracranial Aneurysms and Subarachnoid Hemorrhage. Section IV. Cerebral angiography. An analysis of the diagnostic value and complications of carotid and vertebral angiography in 5484 patients. J Neurosurg 25:98, 1966.

27. Perria L, Davini V, Grudeli R - Indications operatoires dans les ancvrysmes multiples intra-craniens. Neuro-Chirurgie $3: 311,1957$.

28. Poppen JL, Fager CA - Multiple intracranial aneurysms. J Neurosurg 16:581, 1959.

29. Pouyanne H, Banayan A, Got M, Guèrin J, Riemens V - Les anevrysmes sacculaires multiples du système carotidien supra-clinoldien: étude anatomo-clinique et therapeutique. Neuro-Chirurgie 19 (Supp! 1):1, 1973.

30. Samson DS, Hodosh RM, Clarck WK - Surgical management of unruptured asymptomatic aneurysms. J Neurosurg $46: 731,1977$.

31. Stroobandt G, Cornelis G, Thauvoy C - Les anevrysmes intracraniens multiples: $I$. Evolution et orientation actuelle du traitment chirurgicale. Acta Neurol Belg 73:298, 1973.

32. Wood E - Angiographic identification of the ruptured lesoin in patients with multiple cerebral aneurysms. J Neurosurg 21:182, 1964.

33. Weisberg LA - Computed tomography in aneurysmal subarachnoid hemorrhage. Neurology $29: 802,1979$.

34. Yasargil MG, Fox JL - The microsurgical approach to intracranial aneurysms. Surg Neurol 3:7, 1975.

35. Yoshimoto T, Kayama T, Kodama N, Suzuki J - Distribution of intracranlal aneurysms. Tohoku J Exp Med 126:125, 1978.

36. Yoshimoto T, Uchida K, Kaneko U, Kayama T, Suzuki J - An analysis of follow-up results of 1000 intracranial saccular aneurysms with definitive surgical treatment. $J$ Neurosurg 50:152, 1975. 